\title{
Pipeline embolization device for recurrence of previously treated aneurysms
}

\author{
David Dornbos III, MD, Constantine L. Karras, BA, Nicole Wenger, BA, Blake Priddy, BS, \\ Patrick Youssef, MD, Shahid M. Nimjee, MD, PhD, and Ciarán J. Powers, MD, PhD \\ Department of Neurological Surgery, The Ohio State University Wexner Medical Center, Columbus, Ohio
}

\begin{abstract}
OBJECTIVE The utilization of the Pipeline embolization device (PED) has increased significantly since its inception and original approval for use in large, broad-necked aneurysms of the internal carotid artery. While microsurgical clipping and advances in endovascular techniques have improved overall efficacy in achieving complete occlusion, recurrences still occur, and the best modality for retreatment remains controversial. Despite its efficacy in this setting, the role of PED utilization in the setting of recurrent aneurysms has not yet been well defined. This study was designed to assess the safety and efficacy of PED in the recurrence of previously treated aneurysms.

METHODS The authors reviewed a total of 13 cases in which patients underwent secondary placement of a PED for aneurysm recurrence following prior treatment with another modality. The PEDs were used to treat aneurysm recurrence or residual following endovascular coiling in 7 cases, flow diversion in 2, and microsurgical clipping in 4 . The mean time between initial treatment and retreatment with a PED was 28.1 months, 12 months, and 88.7 months, respectively. Clinical outcomes, including complications and modified Rankin Scale (mRS) scores, and angiographic evidence of complete occlusion were tabulated for each treatment group.
\end{abstract}

RESULTS All PEDs were successfully placed without periprocedural complications. The rate of complete occlusion was $80 \%$ at 6 months after PED placement and $100 \%$ at 12 months in these patients who underwent PED placement following failed endovascular coiling; there were no adverse clinical sequelae at a mean follow-up of 26.1 months. In the 2 cases in which PEDs were placed for treatment of residual aneurysms following prior flow diversion, 1 patient demonstrated asymptomatic vessel occlusion at 6 months, and the other exhibited complete aneurysm occlusion at 12 months. In patients with aneurysm recurrence following prior microsurgical clipping, the rate of complete occlusion was $100 \%$ at 6 and 12 months, with no adverse sequelae noted at a mean clinical follow-up of 27.7 months.

CONCLUSIONS The treatment of recurrent aneurysms with the PED following previous endovascular coiling, flow diversion, or microsurgical clipping is associated with a high rate of complete occlusion and minimal morbidity.

https://thejns.org/doi/abs/10.3171/2017.3.FOCUS1744

KEY WORDS intracranial aneurysm; recurrence; flow diversion

$\mathrm{T}$ HE treatment of intracranial aneurysms has increasingly shifted away from open microsurgery as endovascular techniques and technologies have continued to improve. The introduction of flow diversion marked another major paradigm shift in the neurosurgical treatment of intracranial aneurysms. Initially approved for the treatment of large, broad-necked aneurysms of the petrous to supraclinoid internal carotid artery (ICA), ${ }^{2,21}$ utilization of the Pipeline embolization device (PED, Covidien/ev3) has been described in numerous other locations and aneurysm subtypes. In addition to treatment of unruptured large, broad-necked aneurysms, several studies have evaluated the use of PEDs in the treatment of aneurysm recurrence following prior treatment with endovascular or open microsurgical modalities.

One of the greatest pitfalls in the treatment of intracranial aneurysms with standard coils or stent-assisted coiling is the high recurrence rate, with recurrence rates of 13\%$48 \%$ and retreatment in up to $13 \%$ of previously coiled aneurysms. ${ }^{4,13,24}$ Microsurgical clipping is largely regarded as

ABBREVIATIONS ICA = internal carotid artery; $\mathrm{MCA}=$ middle cerebral artery; $\mathrm{mRS}=$ modified Rankin Scale; PED = Pipeline embolization device; PRU = platelet reactivity unit; $\mathrm{SAH}=$ subarachnoid hemorrhage. 
the most robust option, resulting in complete obliteration in up to $87 \%$ of cases and a retreatment rate of around $4.5 \% .{ }^{24}$ While microsurgical clipping certainly provides a more durable result, aneurysm recurrence following clipping is associated with a substantial hemorrhage rate of $50 \%{ }^{23}$ Debate as to the best treatment modality following recurrence of a previously treated aneurysm certainly exists, although the low morbidity and reconstructive potential of the PED have produced an intriguing option.

The PED was designed as a flexible low-porosity endoluminal stent with the ability to reduce hemodynamic flow between the parent artery and aneurysm, promoting aneurysm thrombosis, allowing flow to branch arteries, and providing a scaffold for intimal overgrowth. This reconstructive potential, low associated morbidity and high efficacy in achieving aneurysm occlusion has garnered substantial popularity for this treatment modality. With complete obliteration of $86 \%$ and retreatment only seen in $2.8 \%$ of patients, PED outcomes are similar to those observed in microsurgical clipping and significantly improved in comparison with other endovascular therapies. ${ }^{6}$ Despite the highly efficacious results, the role of PED utilization in the setting of recurrent aneurysms has not yet been well defined. This study assesses the safety and efficacy of PED as a second-line treatment for aneurysm recurrence following endovascular or microsurgical treatment.

\section{Methods \\ Patient Population}

Institutional review board approval was obtained for the study protocol. Patients with intracranial aneurysms treated with the PED between July 2011 and November 2016 at a single institution were reviewed. Thirteen patients with previously treated aneurysms that were secondarily treated with a PED were retrospectively identified. PED treatment is routinely offered to patients with complex, large, wide-necked aneurysms of the ICA from the petrous through the supraclinoid segment. Baseline patient, aneurysm, and procedural characteristics were recorded.

\section{Procedure}

At least 7 days prior to intervention, patients were started on $75 \mathrm{mg}$ clopidogrel and $325 \mathrm{mg}$ aspirin daily. Baseline preprocedural platelet reactivity unit (PRU) values were assessed. Platelet function tests were performed for all patients using a P2Y12 assay (VerifyNow, Accumetrics), and the PED procedure was performed if the PRU value was within the therapeutic window $(60-240) .{ }^{10}$ During the procedure, an initial bolus of heparin was administered, and the activated clotting time was maintained at at least twice the patient's baseline level. Following the procedure, heparin was discontinued, but the treatment was not pharmacologically reversed. Patients were maintained on dual-antiplatelet therapy for at least 3 months, and aspirin therapy was continued indefinitely.

PED placement was performed under general anesthesia. Angiography was obtained to assess the dimensions of the recurrent aneurysm and to appropriately size the PED to the width of the inflow vessel to avoid any endoleak. Femoral artery access was obtained with a 6-Fr introducer sheath. A triaxial system was used, with a 6-Fr shuttle sheath (Cook Medical) placed in the cervical segment of the vessel proximal to the intracranial vessel of interest, followed by a 0.072-inch (inner diameter) Navien catheter (Covidien/ev3). Finally, a Marksman microcatheter (Covidien/ev3) was advanced over a Traxcess microwire (MicroVention) until adequate placement at the distal landing zone, and the PED was then deployed. This triaxial system was routinely used for PED deployment to maximize support during forward loading of the system. PED deployment was performed under angiographic surveillance, and postdeployment angiography confirmed adequate placement across the aneurysm neck and documented patency of the intracranial vasculature. The number of stents was left to the operator's discretion, although the use of multiple stents is typically reserved for fusiform aneurysms or a malpositioned device. Patients were evaluated overnight in the neurocritical care unit for any periprocedural complications.

\section{Outcomes}

All patients had at least 6 months of follow-up. All procedural and postprocedural complications were documented. Delayed complications and clinical outcomes were recorded during follow-up, at 1, 6, and 12 months after PED placement. Clinical outcomes were assessed based on modified Rankin Scale (mRS) scores, and the score obtained at the most recent clinical follow-up visit was used for analysis. Angiographic outcomes were assessed between 3 and 6 months following the procedure and then again at 1 and 3 years. Aneurysm occlusion was classified as complete (Raymond 1), partial (Raymond 2), or incomplete (Raymond 3).

\section{Results}

\section{Patient Characteristics}

The mean age of the patients was 46.9 years (range 12-71 years, Table 1$)$. Seven patients were male (53.8\%), and 6 were female $(46.2 \%)$. The mean aneurysm size was $7.5 \mathrm{~mm}$ (range 2.0-25.0 mm). Aneurysm morphology included saccular $(n=9)$, blister $(n=1)$, and fusiform $(n=4)$. One patient harbored 2 recurrent aneurysms, which were treated with a single PED. Aneurysm locations involved the carotid ophthalmic $(n=5)$, paraclinoid carotid $(n=3)$, posterior communicating $(\mathrm{n}=2)$, anterior choroidal $(\mathrm{n}=$ $1)$, cavernous carotid $(n=1)$, petrous carotid $(n=1)$, and middle cerebral $(n=1)$ arteries.

\section{Treatment}

Seven patients had undergone primary endovascular coiling in their initial procedure. Four of these patients $(57.1 \%)$ initially presented with subarachnoid hemorrhage (SAH), one of which was secondary to a traumatic pseudoaneurysm. The mean length of time since initial treatment in the coil group was 28.1 months (range 1-84 months). Among those patients presenting with $\mathrm{SAH}$, the mean length of time between initial and subsequent treatment was 7.0 months (range 1-17 months). Three patients were 
TABLE 1. Patient characteristics and indications for treatment

\begin{tabular}{cclllccc}
\hline Case No. & Age (yrs), Sex & Aneurysm Location & Initial Status & Prior Tx & Time From Initial Tx (mos) & Max Diameter (mm) & Indication for Re-Tx* \\
\hline 1 & $46, \mathrm{M}$ & Lt OA & Ruptured & Coiling & 17 & 4.2 & Residual \\
\hline 2 & $55, \mathrm{M}$ & Lt PCoA & Ruptured & Coiling & 9 & 4.1 & Residual \\
\hline 3 & $28, \mathrm{M}$ & Rt paraclin ICA & Ruptured & Coiling & 1 & 11.2 & Recanalization \\
\hline 4 & $36, \mathrm{M}$ & Lt paraclin ICA & Ruptured & Coiling & 1 & 3.6 & Residual \\
\hline 5 & $55, \mathrm{~F}$ & Lt paraclin ICA & Unruptured & Coiling & 20 & 2.9 & Recanalization \\
\hline 6 & $57, \mathrm{M}$ & Lt OA & Unruptured & Coiling & 65 & 5.9 & Recanalization \\
\hline 7 & $48, \mathrm{~F}$ & Rt OA & Unruptured & Coiling & 84 & 13.7 & Recanalization \\
\hline 8 & $54, \mathrm{~F}$ & Lt OA & Ruptured & Clipping & 204 & 74 & Recanalization \\
\hline 9 & $56, \mathrm{~F}$ & Rt OA, rt PCoA & Unruptured & Clipping & 74 & $6.4 ; 4.1$ & Recanalization \\
\hline 10 & $57, \mathrm{~F}$ & Lt AChA & Unruptured & Clipping & 70 & 1.4 & Recanalization \\
\hline 11 & $12, \mathrm{~F}$ & Rt MCA & Unruptured & Clipping & 7 & 15.3 & Residual \\
\hline 12 & $71, \mathrm{M}$ & Lt cav ICA & Unruptured & FD & 17 & 10.9 & Residual \\
\hline 13 & $35, \mathrm{M}$ & Rt petr ICA & Unruptured & FD & Residual \\
\hline
\end{tabular}

$\mathrm{AChA}=$ anterior choroidal artery; cav = cavernous; $\mathrm{FD}=$ flow diversion; $\mathrm{OA}=$ ophthalmic artery; paraclin = paraclinoid; $\mathrm{PCoA}=$ posterior communicating artery; petr $=$ petrous; $T x=$ treatment.

* Aneurysms were classified as "recanalization" if at least 1 diagnostic angiogram demonstrated complete aneurysm occlusion prior to demonstration of recurrence.

treated for residual aneurysms that failed to completely occlude following prior treatment (Fig. 1). The other 4 patients experienced recanalization of an aneurysm that had demonstrated complete occlusion on prior angiography. Based on aneurysm location, endovascular treatment was preferred over microsurgical clipping, and given the prior failed treatment attempts, PED placement was undertaken to provide a scaffold for intimal overgrowth.

Four patients with 5 aneurysms had previously undergone microsurgical clipping, performed in the setting of $\mathrm{SAH}$ in 1 case. The mean time to treatment of aneurysm recurrence was 88.7 months (range 7-204 months). Four aneurysms were recurrent in nature, having angiographic documentation of prior complete occlusion. These were all initially treated at another institution, and given the significant amount of time since the initial surgery, endovascular means for further treatment was preferred. One patient was treated with microsurgical clipping of a giant middle cerebral artery (MCA) bifurcation aneurysm, and complete obliteration could not be achieved at that time (Fig. 2). The broad-necked remnant was most amenable to PED treatment, despite its MCA location.

Two patients with fusiform pseudoaneurysms had undergone prior treatment with PED, with a mean time since treatment of 12 months (range 7-17 months). One of these patients (Case 12) initially presented with a sixth cranial nerve palsy, while the other (Case 13, Fig. 3) initially presented with a dissecting pseudoaneurysm. Both patients demonstrated a substantial decrease in aneurysm size, although with a significant degree of residual, following the initial PED procedure. Residual aneurysm was predominantly located at the proximal and distal regions of prior treatment, and given the marked improvement following initial PED placement, additional PED placement was pursued.

The mean number of PEDs used was 1.3 (range 1-2) for saccular and blister aneurysms and 3 (range 1-5) for fusiform aneurysms.

\section{Clinical and Angiographic Outcomes}

There were no periprocedural complications in any group treated for recurrent aneurysms. Among the $7 \mathrm{pa}-$ tients previously treated with endovascular coiling, 1 patient was lost to follow-up. Of the 6 patients in this group who did have angiographic evaluation (Table 2), 5 under-

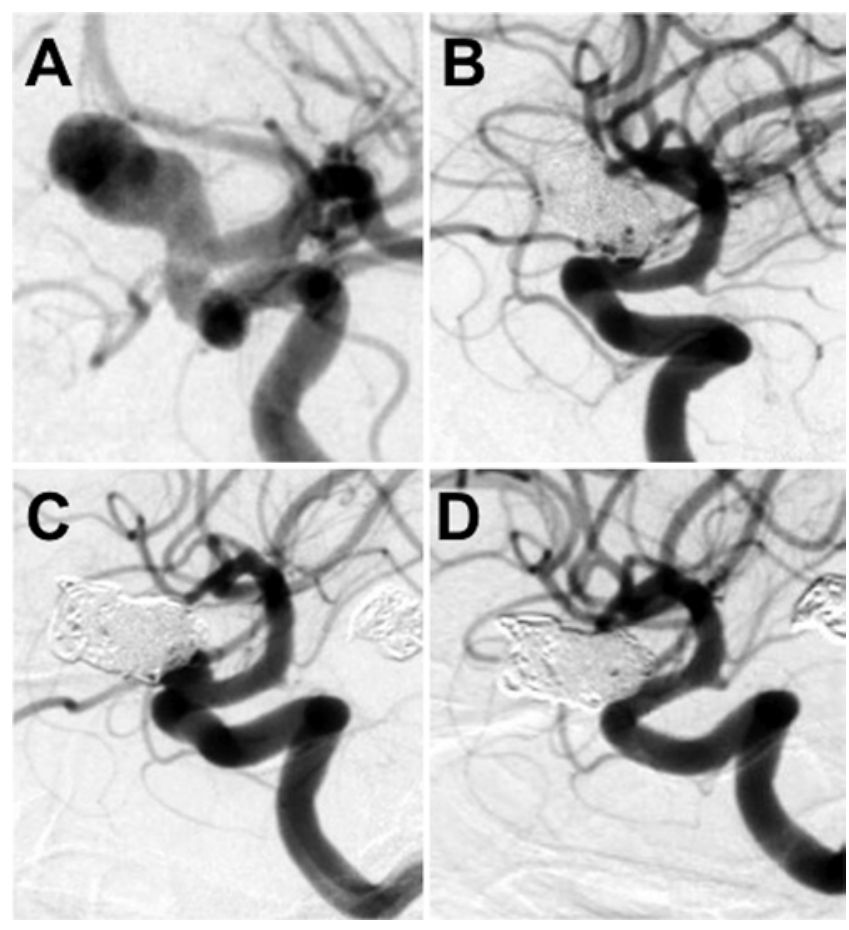

FIG. 1. Case 1. PED treatment for aneurysm residual following prior endovascular coiling. Left ICA digital subtraction angiography (lateral view). This patient initially presented with a ruptured left ophthalmic aneurysm (A), which was subsequently coiled (B), leaving a small neck remnant. Due to growth of the residual aneurysm (C), a PED was placed, resulting in complete occlusion at 6 months' follow-up (D). 


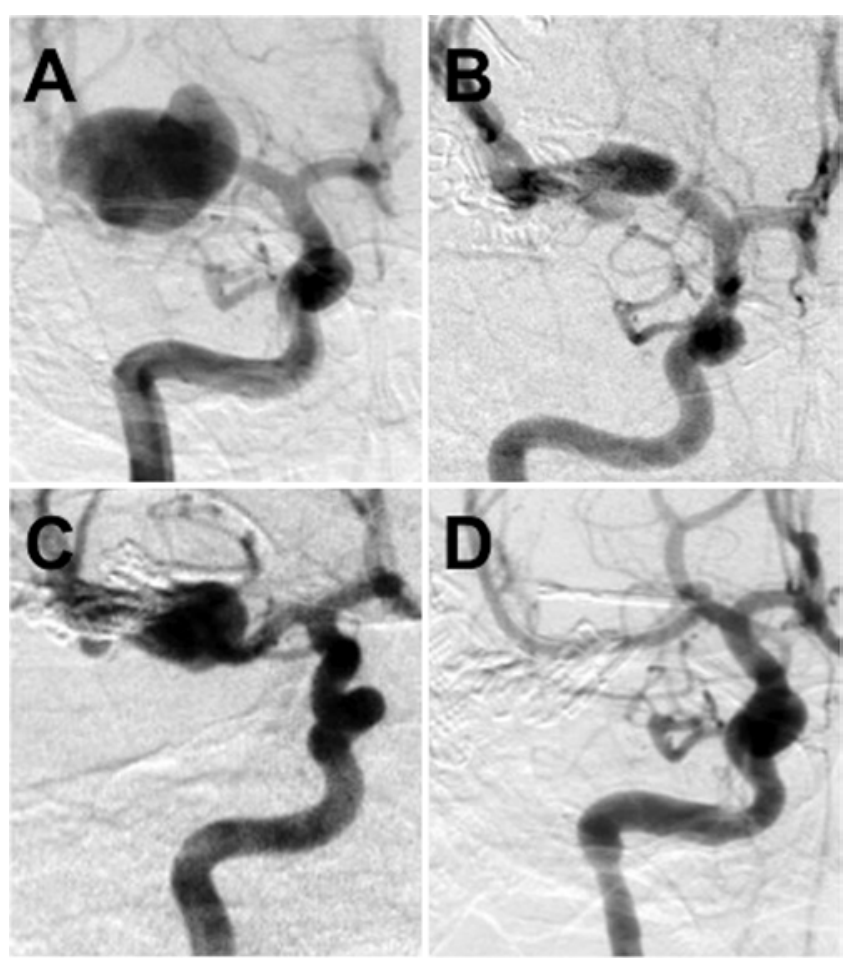

FIG. 2. Case 11. PED treatment for aneurysm residual following prior microsurgical clipping. Right ICA digital subtraction angiography (anteroposterior [AP] view). This patient initially presented with an unruptured right giant MCA bifurcation aneurysm (A), which was subsequently clipped, leaving a small neck remnant (B). Due to growth of the residual aneurysm (C), a PED was placed, resulting in complete occlusion at 6 months' follow-up (D).

went angiography at 6 months after PED treatment, with complete occlusion seen in $4(80 \%)$ of 5 cases, and 5 had radiographic follow-up at 12 months, with all 5 (100\%) of these studies demonstrating complete occlusion. The single patient with Raymond 2 filling at 6 months did undergo repeat angiography at 12 months, and the repeat study demonstrated complete occlusion. No delayed complications were observed with a mean follow-up of 26.1 months
TABLE 2. Radiographic and clinical outcomes following PED treatment for recurrent previously treated aneurysms

\begin{tabular}{|c|c|c|c|c|}
\hline \multirow{2}{*}{$\begin{array}{c}\text { Case } \\
\text { No. }\end{array}$} & \multicolumn{2}{|c|}{ Angiogram Results } & \multicolumn{2}{|c|}{ mRS Score } \\
\hline & 6 Mos & Latest FU (mos) & Pre-PED & Latest FU (mos) \\
\hline 1 & Complete & Complete (16) & 0 & $0(36)$ \\
\hline 2 & Partial & Complete (15) & 0 & $0(30)$ \\
\hline 3 & Complete & Complete (21) & 5 & $5(21)$ \\
\hline 4 & Complete & Complete (19) & 5 & $2(19)$ \\
\hline 5 & $\mathrm{NA}$ & NA & 0 & NA \\
\hline 6 & NA & Complete (13) & 0 & $0(13)$ \\
\hline 7 & Complete & NA & 0 & $0(6)$ \\
\hline 8 & Complete & Complete (31) & 0 & $0(31)$ \\
\hline 9 & Complete & Complete (15) & 0 & $0(24)$ \\
\hline 10 & Complete & Complete (37) & 0 & $0(37)$ \\
\hline 11 & Complete & Complete (22) & 0 & $0(22)$ \\
\hline 12 & Complete & NA & 3 & $6(8)$ \\
\hline 13 & NA & Complete (13) & 0 & $0(13)$ \\
\hline
\end{tabular}

FU = follow-up; NA = not applicable.

Aneurysm occlusion is classified as either complete or partial. One patient (Case 5) was lost to follow-up.

(range 6-53 months). Four patients had a preprocedural and postprocedural mRS score of 0 . Two patients presented with mRS score of 5, with one improving to an mRS score of 2 postprocedurally. The patient lost to follow-up presented with an $\mathrm{mRS}$ score of 0 .

Regarding the 4 patients who had previously undergone microsurgical clipping, complete occlusion was seen in all $4(100 \%)$ on 6- and 12-month follow-up angiography. There were no delayed complications, with a mean clinical follow-up of 27.7 months (range 21-33 months). All 4 patients had preprocedural and postprocedural mRS scores of 0 .

Regarding the 2 patients treated with PED following failed prior PED treatment, 1 patient had complete occlusion of the ICA at 6 months' follow-up, although with no new clinical sequelae. The other patient experienced com-

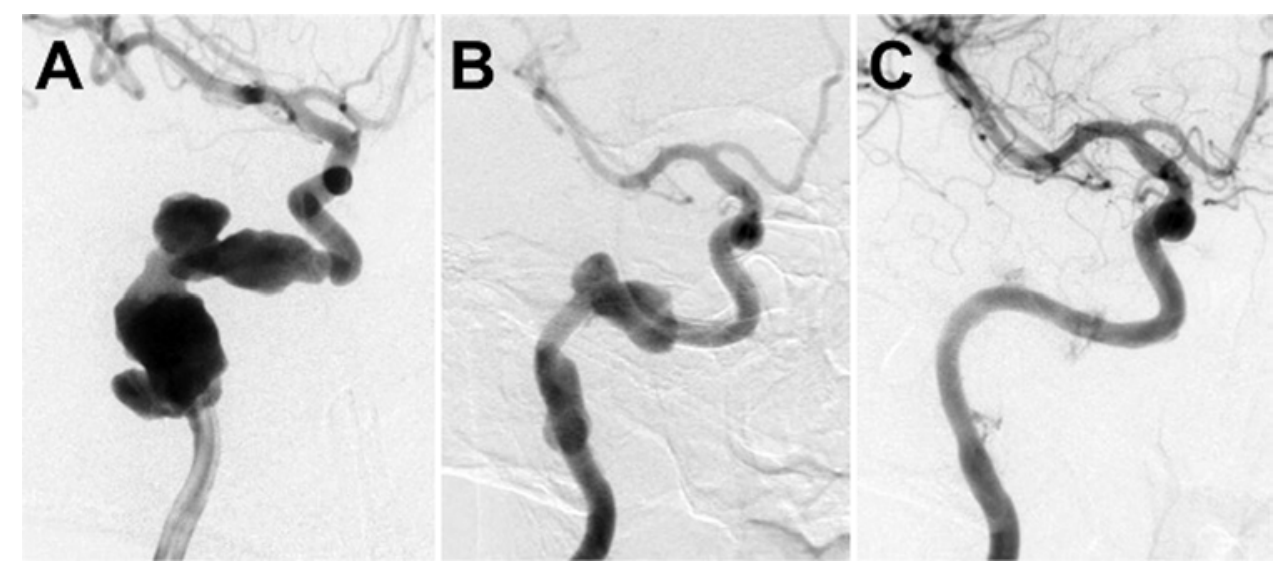

FIG. 3. Case 13. PED treatment for aneurysm residual following prior PED treatment. Right ICA digital subtraction angiography (AP view). This patient presented following a fall with a dissecting pseudoaneurysm of the right petrous ICA (A), which was treated with 4 telescoping PEDs. Follow-up angiography revealed diminished size of the pseudoaneurysm, although with some residual, which was treated with 2 additional PEDs (B). Complete occlusion was seen at 13 months' follow-up (C). 
plete aneurysm occlusion, with an mRS score of 0 and clinical follow-up of 17 months.

\section{Discussion}

The introduction of the PED revolutionized intracranial aneurysm management, particularly for large, widenecked aneurysms of the ICA. The efficacy of this device, achieving a high aneurysm occlusion rate of $93 \%-94 \%$, has made it a particularly appealing tool in endovascular neurosurgery. ${ }^{20,21,25}$ The significant recurrence rate in previously treated aneurysms has prompted an increased use of the PED in these aneurysms as a second-line treatment. Despite the overwhelming efficacy in untreated aneurysms, initial experience demonstrated decreased efficacy in previously treated aneurysms with a reported $68.7 \% \%^{20}$ complete occlusion rate and prior treatment as a predictor of PED treatment failure. ${ }^{22}$ While prior treatment failure certainly places the patient at risk for further recurrence, the PED provides a distinct advantage in restoring physiological cerebral flow dynamics and providing a scaffold for endothelialization. In fact, numerous studies have demonstrated equivalent efficacy for the use of PEDs in treatment-naïve and recurrent aneurysms alike.

\section{PED Following Failed Endovascular Coiling}

Few studies have specifically evaluated the safety and efficacy of PED treatment following recurrence of previously coiled aneurysms. Nonetheless, placement of a PED as a secondary treatment following failure of endovascular coiling has a reported efficacy of $69 \%-93.3 \%,,^{2,5,9,11,14,18,20,21}$ although many of these studies pooled initial treatments into a single cohort for evaluation. The only studies evaluating the outcome of PED placement in this specific subgroup of recurrent aneurysms in isolation (Table 3) revealed a complete obliteration of $76.7 \%{ }^{9}$ and $69.2 \% .^{18}$ When combined with those demonstrating near-complete occlusion (>90\%), this increased to $86.7 \%$ and $100 \%$, respectively, consistent with radiographic outcomes for PED placement in untreated aneurysms ${ }^{6}$ and with those seen in microsurgical clipping. ${ }^{24}$ Similarly, among those patients treated with a PED following endovascular coiling at our institution, $80 \%$ demonstrated complete occlusion at 6 months, and $100 \%$ demonstrated complete occlusion at 1 year. No adverse clinical sequelae were observed, a result consistent with prior published reports in this subgroup. While both ischemic and hemorrhagic complications have been observed, the risk of significant neurological sequelae appears to be 3\%-5.6\%., ${ }^{2,9}$ Furthermore, our patients had no further recurrence or clinical symptomatology at a mean follow-up of 26.1 months, revealing that endovascular treatment with PED for recurrent previously coiled aneurysms is a safe, effective, and durable treatment option. For patients initially presenting with ruptured aneurysms, at which time PED placement carries substantial risk, treatment with a PED following failed endovascular coiling provides a scaffold for neointimal formation and vessel reconstruction, generating a more durable result.

\section{PED Following Failed Stent-Assisted Coiling}

Numerous studies have evaluated the safety and effi-
TABLE 3. Outcomes of PED treatment for recurrent previously treated aneurysms

\begin{tabular}{|c|c|c|c|}
\hline Prior Tx \& Authors & $\begin{array}{l}\text { No. } \\
\text { of } \\
\text { Pts }\end{array}$ & $\begin{array}{l}\text { Complete } \\
\text { Occlusion }\end{array}$ & Clinical Outcome \\
\hline \multicolumn{4}{|l|}{ Primary coiling } \\
\hline Daou et al., 2015 & 33 & $76.7 \%$ & $3 \%$ IPH (1) \\
\hline Kühn et al., 2016 & 18 & $69.2 \%$ & No sequelae \\
\hline \multicolumn{4}{|l|}{$\begin{array}{l}\text { Stent or stent-assisted } \\
\text { coiling }\end{array}$} \\
\hline Fischer et al., 2012 & 30 & $65 \%$ & 13\%; CVA (2), IPH (2) \\
\hline Daou et al., 2016 & 21 & $55.6 \%$ & 14.3\%; CVA (2), IPH (1) \\
\hline $\begin{array}{l}\text { Heiferman et al., } \\
\quad 2016\end{array}$ & 25 & $38 \%$ & 8\%; TIA (1), IPH (1) \\
\hline \multicolumn{4}{|l|}{ FD } \\
\hline Becske et al., 2016 & 4 & $50 \%$ & Not reported \\
\hline \multicolumn{4}{|l|}{ Microsurgical clipping } \\
\hline Ding et al., 2014 & 2 & $50 \%$ & No sequelae \\
\hline Adeeb et al., 2016 & 7 & $100 \%$ & No sequelae \\
\hline Kalani et al., 2016 & 2 & $100 \%$ & No sequelae \\
\hline Kühn et al., 2016 & 6 & $60.0 \%$ & No sequelae \\
\hline Gross et al., 2017 & 8 & $100 \%$ & Fatal distal hemorrhage (1) \\
\hline
\end{tabular}

$\mathrm{CVA}=$ ischemic cerebrovascular accident; $\mathrm{IPH}=$ intraparenchymal hemorrhage; IVH = intraventricular hemorrhage; pts = patients; TIA = transient ischemic attack.

Studies directly evaluating the clinical and radiographic outcomes of patients secondarily treated with the PED following failed primary coiling, stent-assisted coiling, flow diversion, or microsurgical clipping. Values in parentheses are numbers of cases.

cacy of PED placement for aneurysm recurrence following previous treatment with either stenting alone or stentassisted coiling. ${ }^{5,8,14,16,19-21}$ While this has been described in numerous reports, 3 published studies directly evaluated the safety and efficacy of PED in this subset of recurrent aneurysms (Table 3). In achieving complete aneurysm occlusion, reported efficacy ranged from $38 \%$ to $65 \%$, a significantly lower rate than would be expected in PED use for treatment-naïve aneurysms. ${ }^{8,14,16}$ The incidence of significant adverse neurological sequelae tends to be substantially higher for previously stented aneurysms as well. Such sequelae, including transient ischemic attacks and major ischemic and hemorrhagic events, were observed in $8 \%-14.3 \%$ of cases. The presence of a stent in situ may hamper proper deployment and full wall apposition of the PED, decreasing its efficacy and increasing thrombogenicity. Due to this, certain techniques have been suggested, such as balloon angioplasty or distal placement of the intermediate catheter, which may improve delivery of the PED within a prior stent. ${ }^{5,19}$ Nonetheless, providers should be aware that utilization of a PED for recurrence following stent placement appears to be less effective than in untreated aneurysms and may carry a worse safety profile.

\section{PED Following Failed Flow Diversion}

Recurrent or residual aneurysms following PED placement can often be successfully treated with de-escalation 
of the dual-antiplatelet regimen. When this fails to allow aneurysm occlusion, further treatment measures may need to be undertaken. Given that the PED is still in its infancy, little literature exists regarding PED failures and treatment options for recurrent aneurysms following prior PED apart from a few case reports. ${ }^{37,15}$ In a study evaluating the treatment of 119 unruptured aneurysms with a PED, 7 patients experienced occlusion failure, and in 3 of the 7 cases, this residual was treated with a second PED? ${ }^{7}$ Unfortunately, adequate follow-up to assess the durability of this second treatment was not available. When evaluating the 3-year follow-up results for the Pipeline for Uncoilable or Failed Aneurysms (PUFS) trial, the investigators found that 15 patients had a residual aneurysm or residual neck. Four of these patients underwent further treatment with a second PED (Table 3), ${ }^{3}$ and $2(50 \%)$ of these 4 progressed to complete occlusion. The 2 patients treated with PEDs at our institution following failed flow diversion each presented with large fusiform aneurysms of the ICA, requiring multiple stents during their first and second treatments. Both patients primarily exhibited residual aneurysm at the proximal and distal portion of the treated segment, which largely guided the decision to place additional stents specifically at these sites. Given this significant amount of intraluminal metal, it is perhaps not surprising that 1 patient had complete vessel occlusion. Nonetheless, particularly in fusiform aneurysms, the reconstructive ability of PEDs makes them an attractive option.

\section{PED Following Failed Microsurgical Clipping}

Microsurgical clipping has long been regarded as the most efficacious and durable option for complete aneurysm occlusion. While the rate of aneurysm obliteration following clipping is $87 \%$, retreatment rates hover around $4.5 \%,{ }^{24}$ and aneurysms that recur following microsurgical clipping carry substantial morbidity with a hemorrhage rate of nearly $50 \% .{ }^{23} \mathrm{~A}$ number of case reports and series have demonstrated efficacy in PED treatment of recurrent aneurysms following prior clipping with minimal complications. ${ }^{1,5,12,14,15,17,18,20}$ Among studies that have specifically evaluated outcomes following PED treatment in this recurrent subtype (Table 3), reported rates of complete aneurysm occlusion have ranged from $50 \%$ to $100 \%$. ${ }^{1,12,15,17,18}$ One patient developed a fatal distal hemorrhage shortly after the procedure, although no other complications were observed. ${ }^{15}$ Similarly, our experience with the use of PEDs in these patients has been overwhelmingly positive, with a $100 \%$ rate of complete occlusion and no adverse complications. Given our mean duration of follow-up of 27.7 months for these patients, this treatment appears to be both durable and highly effective.

\section{Limitations}

This study has several limitations. First, the retrospective nature of the study introduces potential bias. Second, this study reveals outcomes from a single institution with significant experience in flow diversion techniques. Finally, the number of patients, particularly those treated with PED following failed prior flow diversion treatment, is quite limited. While interpretation of treatment results based on this small population must remain guarded, the observed outcomes are similar to those reported for other published studies.

\section{Conclusions}

The introduction of the PED marked a significant paradigm shift in the endovascular treatment of intracranial aneurysms. PED treatment of a recurrent aneurysm following a prior failed stent appears to be less effective than PED use in untreated aneurysms while carrying a worse safety profile. The treatment of recurrent aneurysms following previous endovascular coiling, flow diversion, or microsurgical clipping is associated with a high rate of complete occlusion and minimal morbidity.

\section{References}

1. Adeeb N, Griessenauer CJ, Moore J, Stapleton CJ, Patel AB, Gupta R, et al: Pipeline Embolization Device for recurrent cerebral aneurysms after microsurgical clipping. World Neurosurg 93:341-345, 2016

2. Becske T, Kallmes DF, Saatci I, McDougall CG, Szikora I, Lanzino G, et al: Pipeline for uncoilable or failed aneurysms: results from a multicenter clinical trial. Radiology 267:858868, 2013

3. Becske T, Potts MB, Shapiro M, Kallmes DF, Brinjikji W, Saatci I, et al: Pipeline for uncoilable or failed aneurysms: 3 -year follow-up results. J Neurosurg [epub ahead of print October 14, 2016. DOI: 10.3171/2015.6.JNS15311]

4. Campi A, Ramzi N, Molyneux AJ, Summers PE, Kerr RS, Sneade M, et al: Retreatment of ruptured cerebral aneurysms in patients randomized by coiling or clipping in the International Subarachnoid Aneurysm Trial (ISAT). Stroke 38:1538-1544, 2007

5. Chalouhi N, Chitale R, Starke RM, Jabbour P, Tjoumakaris S, Dumont AS, et al: Treatment of recurrent intracranial aneurysms with the Pipeline Embolization Device. J Neurointerv Surg 6:19-23, 2014

6. Chalouhi N, Tjoumakaris S, Starke RM, Gonzalez LF, Randazzo C, Hasan D, et al: Comparison of flow diversion and coiling in large unruptured intracranial saccular aneurysms. Stroke 44:2150-2154, 2013

7. Chiu AH, Cheung AK, Wenderoth JD, De Villiers L, Rice H, Phatouros CC, et al: Long-term follow-up results following elective treatment of unruptured intracranial aneurysms with the Pipeline Embolization Device. AJNR Am J Neuroradiol 36: 1728-1734, 2015

8. Daou B, Starke RM, Chalouhi N, Tjoumakaris S, Hasan D, Khoury J, et al: Pipeline embolization device in the treatment of recurrent previously stented cerebral aneurysms. AJNR Am J Neuroradiol 37:849-855, 2016

9. Daou B, Starke RM, Chalouhi N, Tjoumakaris S, Khoury J, Hasan D, et al: The use of the Pipeline Embolization Device in the management of recurrent previously coiled cerebral aneurysms. Neurosurgery 77:692-697, 2015

10. Delgado Almandoz JE, Crandall BM, Scholz JM, Fease JL, Anderson RE, Kadkhodayan Y, et al: Pre-procedure P2Y12 reaction units value predicts perioperative thromboembolic and hemorrhagic complications in patients with cerebral aneurysms treated with the Pipeline Embolization Device. J Neurointerv Surg 5 (Suppl 3):iii3-iii10, 2013

11. Deutschmann HA, Wehrschuetz M, Augustin M, Niederkorn $\mathrm{K}$, Klein GE: Long-term follow-up after treatment of intracranial aneurysms with the Pipeline embolization device: results from a single center. AJNR Am J Neuroradiol 33:481-486, 2012

12. Ding D, Starke RM, Evans AJ, Jensen ME, Liu KC: Endovascular treatment of recurrent intracranial aneurysms following 
previous microsurgical clipping with the Pipeline Embolization Device. J Clin Neurosci 21:1241-1244, 2014

13. Ferns SP, Sprengers ME, van Rooij WJ, Rinkel GJ, van Rijn JC, Bipat S, et al: Coiling of intracranial aneurysms: a systematic review on initial occlusion and reopening and retreatment rates. Stroke 40:e523-e529, 2009

14. Fischer S, Vajda Z, Aguilar Perez M, Schmid E, Hopf N, Bäzner H, et al: Pipeline embolization device (PED) for neurovascular reconstruction: initial experience in the treatment of 101 intracranial aneurysms and dissections. Neuroradiology 54:369-382, 2012

15. Gross BA, Albuquerque FC, Moon K, Ducruet AF, McDougall CG: Endovascular treatment of previously clipped aneurysms: continued evolution of hybrid neurosurgery. J Neurointerv Surg 9:169-172, 2017

16. Heiferman DM, Billingsley JT, Kasliwal MK, Johnson AK, Keigher KM, Frudit ME, et al: Use of flow-diverting stents as salvage treatment following failed stent-assisted embolization of intracranial aneurysms. J Neurointerv Surg 8:692-695, 2016

17. Kalani MY, Albuquerque FC, Levitt M, Nakaji P, Spetzler RF, McDougall C: Pipeline embolization for definitive endoluminal reconstruction of blister-type carotid aneurysms after clip wrapping. J Neurointerv Surg 8:495-500, 2016

18. Kühn AL, de Macedo Rodrigues K, Lozano JD, Rex DE, Massari F, Tamura T, et al: Use of the Pipeline embolization device for recurrent and residual cerebral aneurysms: a safety and efficacy analysis with short-term follow-up. J Neurointerv Surg [epub ahead of print], 2016

19. Mascitelli JR, Wei D, Oxley TJ, Kellner CP, Shoirah H, De Leacy RA, et al: A technical consideration when using flow diversion for recurrent aneurysms following stent-assisted coiling. J Neurointerv Surg [epub ahead of print], 2016

20. McAuliffe W, Wycoco V, Rice H, Phatouros C, Singh TJ, Wenderoth J: Immediate and midterm results following treatment of unruptured intracranial aneurysms with the Pipeline Embolization Device. AJNR Am J Neuroradiol 33:164170, 2012

21. Nelson PK, Lylyk P, Szikora I, Wetzel SG, Wanke I, Fiorella D: The Pipeline Embolization Device for the intracranial treatment of aneurysms trial. AJNR Am J Neuroradiol 32:34-40, 2011
22. O'Kelly CJ, Spears J, Chow M, Wong J, Boulton M, Weill A, et al: Canadian experience with the Pipeline embolization device for repair of unruptured intracranial aneurysms. AJNR Am J Neuroradiol 34:381-387, 2013

23. Owen CM, Montemurro N, Lawton MT: Microsurgical management of residual and recurrent aneurysms after coiling and clipping: an experience with 97 patients. Neurosurgery 62 (Suppl 1):92-102, 2015

24. Spetzler RF, McDougall CG, Albuquerque FC, Zabramski JM, Hills NK, Partovi S, et al: The Barrow Ruptured Aneurysm Trial: 3-year results. J Neurosurg 119:146-157, 2013

25. Szikora I, Berentei Z, Kulcsar Z, Marosfoi M, Vajda ZS, Lee $\mathrm{W}$, et al: Treatment of intracranial aneurysms by functional reconstruction of the parent artery: the Budapest experience with the pipeline embolization device. AJNR Am J Neuroradiol 31:1139-1147, 2010

\section{Disclosures}

The authors report no conflict of interest concerning the materials or methods used in this study or the findings specified in this paper.

\section{Author Contributions}

Conception and design: Dornbos, Powers. Acquisition of data: Dornbos, Karras, Wenger, Youssef, Powers. Analysis and interpretation of data: Dornbos, Karras, Wenger. Drafting the article: Dornbos, Priddy. Critically revising the article: Dornbos, Karras, Wenger, Priddy, Nimjee, Powers. Reviewed submitted version of manuscript: Dornbos, Karras, Wenger, Priddy, Nimjee, Powers. Approved the final version of the manuscript on behalf of all authors: Dornbos. Administrative/technical/material support: Nimjee, Powers. Study supervision: Dornbos, Nimjee, Powers.

\section{Correspondence}

David Dornbos III, Department of Neurological Surgery, The Ohio State University Wexner Medical Center, N1014 Doan Hall, 410 West 10th Ave., Columbus, OH 43210. email: david.dornbos@ osumc.edu. 